\title{
Potent Tyrosinase Inhibitory Activity of Curcuminoid Analogues and Inhibition Kinetics Studies
}

\author{
Anan Athipornchai ${ }^{1}{ }^{(}$, Nattisa Niyomtham ${ }^{2}$, Wachirachai Pabuprapap ${ }^{3}{ }^{\circledR}$, Vachiraporn Ajavakom ${ }^{3}$, Maria Duca ${ }^{4}$, \\ Stéphane Azoulay ${ }^{4, *}$ and Apichart Suksamrarn ${ }^{3, *}$ \\ 1 Department of Chemistry and Center of Excellence for Innovation in Chemistry, Faculty of Science, \\ Burapha University, Bangsaen, Chonburi 20131, Thailand; anana@buu.ac.th \\ 2 International College of Dentistry, Walailak University, Nakhon Si Thammarat 80161, Thailand; \\ nattisa.ni@wu.ac.th \\ 3 Department of Chemistry and Center of Excellence for Innovation in Chemistry, Faculty of Science, \\ Ramkhamhaeng University, Bangkapi, Bangkok 10240, Thailand; wachirachai7@gmail.com (W.P.); \\ a_vachiraporn@ru.ac.th (V.A.) \\ 4 Université Côte d'Azur, CNRS, ICN, 28 Avenue Valrose, CEDEX 2, 06108 Nice, France; \\ maria.duca@univ-cotedazur.fr \\ * Correspondence: stephane.azoulay@univ-cotedazur.fr (S.A.); \\ asuksamrarn@yahoo.com or s_apichart@ru.ac.th (A.S.); Tel.: +33-4-89-15-10-29 (S.A.); +66-81849-8420 (A.S.)
}

check for updates

Citation: Athipornchai, A.; Niyomtham, N.; Pabuprapap, W.; Ajavakom, V.; Duca, M.; Azoulay, S.; Suksamrarn, A. Potent Tyrosinase Inhibitory Activity of Curcuminoid Analogues and Inhibition Kinetics Studies. Cosmetics 2021, 8, 35. https://doi.org/10.3390/ cosmetics 8020035

Academic Editor: Enzo Berardesca

Received: 9 April 2021

Accepted: 28 April 2021

Published: 4 May 2021

Publisher's Note: MDPI stays neutral with regard to jurisdictional claims in published maps and institutional affiliations.

Copyright: (c) 2021 by the authors. Licensee MDPI, Basel, Switzerland. This article is an open access article distributed under the terms and conditions of the Creative Commons Attribution (CC BY) license (https:// creativecommons.org/licenses/by/ $4.0 /)$.
Abstract: Natural tyrosinase inhibitors from herbal plants are promising therapeutic agents for skincare and cosmetic products. Natural curcuminoids exhibit weak antityrosinase properties. The structural modification of curcumin, the major curcuminoid from Curcuma longa, gave 14 analogues. The tyrosinase inhibitory activity of the natural curcuminoids and the modified analogues on both L-tyrosine and DOPA substrates were evaluated. The inhibition kinetics were also undertaken. For analogues with potent activity on the L-tyrosine substrate, the isoxazole analogue $\mathbf{1 2}$ and two reduced analogues, hexahydrocurcumin (16) and the $\alpha, \beta$-unsaturated analogue 17, showed $\mathrm{IC}_{50}$ values of 8.3, 14.6 and $9.4 \mu \mathrm{M}$, and were 20.9-, 11.9- and 18.4-fold more active, respectively, than kojic acid, the reference compound. For the analogues with potent antityrosinase on DOPA substrate, the dimethylated analogue 5 exhibited the strongest antityrosinase activity against the DOPA substrate, with the $\mathrm{IC}_{50}$ value of $8.0 \mu \mathrm{M}$, which was 16.6 -fold more active than kojic acid. The inhibition kinetics revealed that curcuminoid 5 could bind with both free enzyme and with the enzyme-substrate complex. It acted as a competitive-uncompetitive mixed-II type inhibitor. Curcuminoid $\mathbf{1 7}$ could bind with both free enzyme and the enzyme-substrate complex. The results indicated that $\mathbf{1 7}$ acted as a competitive-uncompetitive mixed-I type inhibitor, while curcuminoid $\mathbf{1 2}$ was a noncompetitive inhibitor which bound with both free enzymes and the enzyme-substrate complex. These potent analogues might serve as new potential tyrosinase inhibitors for the prevention and treatment of skin pigmentation disorders.

Keywords: curcuminoid analogues; antityrosinase activity; inhibition kinetics; skin pigmentation disorders

\section{Introduction}

Increasing attention has been focused on the use of natural ingredients from herbal plants for developing into modern medicine and cosmetic products because of their relatively few side effects. Moreover, the pursuit of white skin and healthiness is the latest trend amongst most of the Asian populations, as they want to look younger than their age. Human skin color is determined by the amount of natural pigment, melanin, which is synthesized by the tyrosinase enzyme catalyst.

Tyrosinase, also known as polyphenol oxidase, is a copper-containing monooxygenase enzyme which catalyzes two distinct reactions of melanin biosynthesis, including the ortho-hydroxylation of the amino acid, tyrosine, to 3,4-dihydroxyphenylalanine (DOPA) 
(cresolase or monophenolase activity), and the oxidation of DOPA to ortho-quinone (catecholase or diphenolase activity). The ortho-quinone was also synthesized to melanin pigment by various reactions [1]. Many researchers have been searching for natural tyrosinase inhibitors from herbal plants for skincare and cosmetic products.

Curcuminoids are natural, strong antioxidant polyphenols which are isolated from the rhizomes of Zingiberaceae plants such as Curcuma longa L. The major curcuminoid constituent of this plant is curcumin (1) [2], which exhibits several biological activities such as antioxidant [3], anti-inflammatory [4], anticancer [5], antibacterial [6], antimicrobial [7] and antiviral [8] activities. Recently, several curcuminoids and their analogues have been developed and used as oral supplements for various medical conditions [9]. The safety of curcumin is evident from its consumption for centuries at levels of up to $100 \mathrm{mg} /$ day by people in many countries. In addition, there is much evidence to confirm that curcumin and its derivatives are safe for topical application, and are used in commercially available cosmetic products and for wound healing $[10,11]$. For this reason, the beneficial properties of curcuminoids and their analogues have attracted numerous efforts for development in cosmetics for use as a safe therapeutic agent. The carbocyclic diarylpentanoids, a group of polyphenolic curcumin analogues, have been synthesized and their antityrosinase and antioxidant activities have been evaluated [4,12]. Symmetrical and unsymmetrical carbocyclic curcumin analogues have also been synthesized and their antityrosinase activities have also been determined [13-15]. However, there are few reports on antityrosinase activity of the linear curcumin analogues [16,17]. In this study, aiming the critical roles of the linear curcuminoid analogues as tyrosinase inhibitors, a series of curcumin analogues were synthesized and their tyrosinase inhibitory activity were evaluated. In addition, the inhibition mechanism and structure-activity relationships for the antityrosinase properties of linear curcuminoid analogues were also investigated.

\section{Materials and Methods}

\subsection{Chemical Reagents and General Experimental Procedures}

All chemicals used for the synthesis of the curcuminoid analogues were supplied by Merck (Damstadt, Germany), Fluka (Buchs, Switzerland), or Sigma-Aldrich (St. Louis, MO, USA). Tyrosinase from mushroom (EC 1.14.18.1), L-tyrosine, 3,4-dihydroxy-L-phenylalanine (DOPA), kojic acid and dimethyl sulfoxide (DMSO) were purchased from Sigma-Aldrich (St. Louis, MO, USA). Melting points were determined using an electrothermal melting point apparatus and were uncorrected. IR spectra were recorded in the ATR mode on a Perkin-Elmer FT-IR Spectrum 400 spectrophotometer (PerkinElmer, Waltham, MA, USA). ${ }^{1} \mathrm{H}$ and ${ }^{13} \mathrm{C}$ NMR spectra were recorded on a Bruker AVANCE 400 spectrometer (Bruker, Faellanden, Switzerland) operating at 400 and $100 \mathrm{MHz}$, respectively. Mass spectra were obtained using a Finnigan LC-Q mass spectrometer (Finnigan, Bremen, Germany). High-resolution mass spectra were obtained using a Bruker micrOTOF mass spectrometer (Bruker, Bremen, Germany). Unless indicated otherwise, column chromatography was carried out using Merck silica gel 60 (finer than $0.063 \mathrm{~mm}$ ). For TLC, Merck precoated silica gel $60 \mathrm{~F}_{254}$ plates were used. Spots on TLC were detected under UV light and by spraying with anisaldehyde- $\mathrm{H}_{2} \mathrm{SO}_{4}$ reagent followed by heating. Untreated 96-well plates were obtained from Thermo Scientific Nunc (Illkirch, France). Adhesive films (Greiner Bio-One, Les Ulis, France) were used to cover the plates during incubation. In vitro biological tests were realized in triplicate with the automated system epMotion 5075 (Eppendorf, Montesson, France) and absorbance measurements were carried out using a Spectramax Plus 384 spectrophotometer (Molecular Devices, Wokingham, UK).

\subsection{Chemical Modification of Curcuminoids}

The natural curcuminoids 1-3 were isolated from Curcuma longa rhizomes by the method described previously [18] and were used in chemical modifications to the analogues 4-17 for antityrosinase evaluations. The diacetate 4, dimethyl ether 5 , the hydroxyethyl ether 6, the didemethyl ether 7 and the reduced curcuminoid analogues 15-17 were synthe- 
sized by the literature procedures [18]. The pyrazoles $\mathbf{8 - 1 0}$ and the isoxazoles 11-14 were modified from the corresponding curcuminoids 1-3 [19]. The ${ }^{1} \mathrm{H}$ and ${ }^{13} \mathrm{C}$ NMR spectra of all compounds are in the Supplementary Materials. (Figures S1-S34)

\subsection{Tyrosinase Inhibition Assay}

Tyrosinase inhibitory activity was determined according to the method as previously described [20] with modifications by measuring the DOPA chrome formed due to the action of tyrosinase enzyme on L-tyrosine and DOPA substrates. Briefly, the assays were performed in 96-well plates as follows. First, $150 \mu \mathrm{L}$ of a solution of mushroom tyrosinase (171.66 $\mathrm{U} \mathrm{mL}^{-1}$ for tyrosine assays and $85.83 \mathrm{U} \mathrm{mL}^{-1}$ for DOPA assays) in phosphate buffer ( $50 \mathrm{mmol} \mathrm{L}^{-1}, \mathrm{pH} 6.8$ ) was distributed in each well (enzyme final concentration per well: $100 \mathrm{U} \mathrm{mL}^{-1}$ ), together with $7.5 \mu \mathrm{L}$ of samples diluted at a concentration of $3.433 \mathrm{mg} \mathrm{mL}^{-1}$ in DMSO (sample final concentration per well: $100 \mu \mathrm{g} \mathrm{mL}{ }^{-1}$ ). Kojic acid $\left(3.433 \mathrm{mmol} \mathrm{L}^{-1}\right.$ in DMSO) was used as the positive control and DMSO alone was used as the negative control (OD control). The plate was filmed and incubated at room temperature for $20 \mathrm{~min}$. A first reading was performed at $480 \mathrm{~nm}$ to obtain ODs from the blank. Then, $100 \mu \mathrm{L}$ of a solution of L-tyrosine $1 \mathrm{mM}$ in phosphate buffer $(\mathrm{pH}=6.8$; final L-tyrosine concentration per well: $0.388 \mathrm{mM}$ ) were distributed in each well. After $20 \mathrm{~min}$ of incubation, OD reading was performed at $480 \mathrm{~nm}$ to assess the percentage of inhibition using the equation 1 below:

The percentage of tyrosinase inhibition $(\%)=\{[(\mathrm{A}-\mathrm{B})-(\mathrm{C}-\mathrm{D})] /(\mathrm{A}-\mathrm{B})\} \times 100$

where $\mathrm{A}$ is the absorbance of the control with the enzyme, $\mathrm{B}$ is the absorbance of the control without the enzyme, $C$ is the absorbance of the test sample with the enzyme and $D$ is the absorbance of the test sample without the enzyme.

\subsection{Kinetic Analysis of Tyrosinase Inhibition Assay}

The kinetic properties of the highly active curcuminoids $(5,12$ and 17) were found using the procedure described above but varying the concentration of L-tyrosine or DOPA as substrates $(0.125,0.25,0.50$ and $1.00 \mathrm{mM})$ and doing a reading every $30 \mathrm{~s}$ after addition of the substrate. The Lineweaver-Burk plot was applied to determine the inhibition mode. The inhibition constant $\left(\mathrm{K}_{\mathrm{I}}\right.$ and $\left.\mathrm{K}_{\mathrm{IS}}\right)$ was determined by the secondary plots of the apparent slope or intercept versus different concentrations of inhibitor [21].

\subsection{Statistical Analysis}

All assays were performed at least three times and in triplicate. The statistical analyses were done using the software GraphPad Prism for Windows, Version 5.03 (GraphPad Software, La Jolla, CA, USA).

\section{Results and Discussion}

\subsection{Chemistry}

Natural curcuminoids 1-3 were isolated from the rhizomes of $C$. longa which were subjected to chemical modifications following our published procedures $[18,19]$ to give 14 synthetic analogues (4-17) for antityrosinase evaluations.

\subsection{Inhibitory Effects on Tyrosinase}

The natural curcuminoids 1, 2 and $\mathbf{3}$ and their synthetic analogues 4-17 were subjected to tyrosinase inhibitory assay by measuring the hydroxylation of L-tyrosine and the oxidation of DOPA substrates to assess monophenolase and diphenolase activities, respectively. Based on the data shown in Table 1, it was found that the natural curcuminoids 1-3 showed moderate to good inhibitory activities against tyrosinase enzyme on both pathways. Against the monophenolase activity, curcumin (1) showed moderate inhibitory effect with $\mathrm{IC}_{50}$ of $326.5 \mu \mathrm{M}$ and the action of demethoxycurcumin (2) was comparable to that of the curcuminoid 1, whereas bisdemethoxycurcumin (3) ( $\left.\mathrm{IC}_{50} 46.5 \mu \mathrm{M}\right)$ was more active than $\mathbf{1}$ and $\mathbf{2}$; it was 10.1-fold more active than compound $\mathbf{2}$ and was 3.7-fold more 
active than the standard kojic acid $\left(\mathrm{IC}_{50} 132.8 \mu \mathrm{M}\right)$. Against the diphenolase activity, compound $3\left(\mathrm{IC}_{50} 34.8 \mu \mathrm{M}\right)$ was more active than $\mathbf{1}$ and $\mathbf{2}$; it was 3.8 -fold more active than kojic acid. The results indicate that the absence of the methoxy group increases tyrosinase inhibitory activity of curcuminoids especially for the monophenolase step, probably due the ability of hydroxyl groups to create a metal-ligand binding interaction with the dicopper nucleus [22].

Table 1. Tyrosinase inhibitory activity of natural curcuminoids (1-3) and synthetic analogues (4-17) on L-tyrosine and DOPA substrates.

\begin{tabular}{|c|c|c|c|}
\hline \multirow{2}{*}{ Compound } & \multirow{2}{*}{ Structure } & \multicolumn{2}{|c|}{ Tyrosinase Inhibitory Activity $\left(\mathrm{IC}_{50} ; \mu \mathrm{M}\right)^{1}$} \\
\hline & & L-tyrosine & DOPA \\
\hline 1 & & 326.5 & 94.8 \\
\hline 2 & & 470.0 & 41.1 \\
\hline 3 & & 46.5 & 34.8 \\
\hline 4 & & Inactive $^{2}$ & Inactive $^{2}$ \\
\hline 5 & & 86.2 & 8.0 \\
\hline 6 & & Inactive $^{2}$ & Inactive $^{2}$ \\
\hline 7 & & 66.9 & 54.6 \\
\hline 8 & & 677.1 & 21.9 \\
\hline 9 & & 154.4 & 19.7 \\
\hline 10 & & 129.1 & 19.2 \\
\hline 11 & & 24.3 & 330.9 \\
\hline
\end{tabular}


Table 1. Cont.

Compound

${ }^{1}$ Standard deviations are not shown, but all are within $10 \%$ of the $\mathrm{IC}_{50}$ value. ${ }^{2}$ Inactive at $1000 \mu \mathrm{M} .{ }^{3}$ Kojic acid was used as the positive control.

The effects of the free hydroxyl group of the oxygen function at the aromatic ring on the tyrosinase inhibition were then investigated. The diacetylated curcuminoid analogue 4 and the dihydroxyethyl ether analogue 6 showed no inhibition on tyrosinase on both substrates, indicating that acetylation and hydroxyethylation of the free hydroxyl groups resulted in a loss of tyrosinase inhibition. In contrast, the methylation of compound 1 to the dimethoxylated analogue $\mathbf{5}$ gave rise to more potent inhibitory activities against tyrosinase on both substrates, especially the DOPA substrate, which exhibited highly potent inhibitory activity on the DOPA substrate at the $\mathrm{IC}_{50}$ value of $8.0 \mu \mathrm{M}, 11.9$-fold more active than the parent 1. It was 16.6-fold more active than kojic acid. The results have indicated that methylation of the hydroxyl group increased tyrosinase inhibition. In addition, the didemethylated curcumin $\mathbf{7}$ was also more active than the parent $\mathbf{1}$. However, it was less active than the dimethoxylated analogue 5 on DOPA substrate and was as active as compound 5 on L-tyrosine substrate.

In order to see the influence of the diketo function on tyrosinase activities, the pyrazole (8-10) and the isoxazole (11-14) analogues were synthesized for the evaluation of antityrosinase activities. For the L-tyrosine substrate, most of the pyrazole analogues were less active than the corresponding parent natural curcuminoids 1-3. The results indicated that the replacement of the $\beta$-diketo function in curcuminoid caused a marked decrease in tyrosinase inhibitory activity on the L-tyrosine substrate. However, for the DOPA substrate, they were more active than the curcuminoids 1-3 and the most active analogue was the pyrazole 10; its $\mathrm{IC}_{50}$ was $19.2 \mu \mathrm{M}$, which was 6.9-fold more active than kojic acid. On the other hand, the isoxazoles $\mathbf{1 1}$ and $\mathbf{1 2}$ were more strongly active than the curcuminoids $\mathbf{1}$ and 3 on L-tyrosine substrate, with the $\mathrm{IC}_{50}$ of 24.3 and $8.3 \mu \mathrm{M}$, respectively. They were 13.4- and 5.6-fold more active than the curcuminoids $\mathbf{1}$ and 3, respectively. However, compounds 11 and 12 were considerably less active than the parent natural curcuminoids 1-3 on DOPA substrate. Moreover, the dimethoxylated isoxazole 13 and the diacetylated 
isoxazole 14 showed no inhibitory activities against tyrosinase on both substrates. The findings indicated that the free hydroxyl groups on the benzene rings are essential for high activity on L-tyrosine substrate. From these results, it was concluded that the presence of the pyrazole ring contributed to high inhibitory activity against tyrosinase on DOPA substrate whereas the presence of the isoxazole ring contributed to high inhibitory activity against tyrosinase on L-tyrosine substrate.

In order to see the influence of the alkene function of the alkyl side chain on antityrosinase activities, the reduced curcuminoid analogues 15-17 were prepared from the curcuminoid 1. The antityrosinase evaluation of these reduced curcuminoids revealed that tetrahydrocurcumin 15 was 6.3-fold more active than the parent curcuminoid 1 on L-tyrosine substrate, but it was less active than compound 1 on the DOPA substrate. In addition, hexahydrocurcumin (16) was 22.3- and 3.7-fold more active than curcumin (1) on L-tyrosine and DOPA substrates, respectively. The $\alpha, \beta$-unsaturated ketone 17 showed highly potent inhibitory activity against tyrosinase on L-tyrosine substrate, with an $\mathrm{IC}_{50}$ value of $9.4 \mu \mathrm{M}$, which was 34.7- and 18.4-fold more active than the parent compound 1 and kojic acid, respectively. However, for the DOPA substrate, compound 17 was only slightly more active than its parent compound $\mathbf{1}$ and kojic acid. From these results, it was concluded that reduced curcuminoid analogues 15-17 contributed to high tyrosinase inhibiting activities on L-tyrosine substrate which could be explained by more adaptative flexibility. The structure-activity relationship (SAR) analysis of curcuminoids and their analogues is summarized in Figure 1.

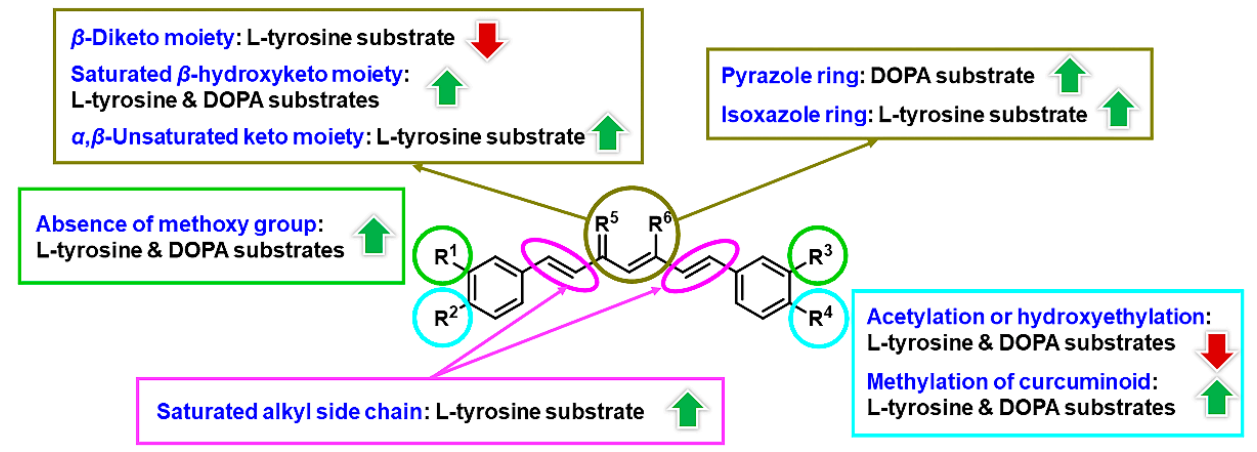

Figure 1. Structure-activity relationship (SAR) analysis of curcuminoids and their analogues.

\subsection{Inhibition Mechanism on the Mushroom Tyrosinase}

The inhibition mechanism on the mushroom tyrosinase was investigated for the best inhibitor through kinetic analysis. The inhibitory types of curcuminoid 5 on mushroom tyrosinase were determined during the oxidation of DOPA from Lineweaver-Burk plots [21], the results of which are summarized in Table 2.

Table 2. The inhibition type and constants of active curcuminoids on mushroom tyrosinase.

\begin{tabular}{cccc}
\hline \multirow{2}{*}{ Compound } & \multirow{2}{*}{ Inhibition Type } & \multicolumn{2}{c}{ Inhibition Constants $(\mu \mathrm{M})$} \\
\cline { 3 - 4 } & & $\mathbf{K}_{\mathbf{I}}$ & $\mathbf{K}_{\mathbf{I S}}$ \\
\hline $\mathbf{5}$ & Mixed-II type & 4.64 & 3.44 \\
$\mathbf{1 2}$ & Non-competitive & 0.12 & 0.08 \\
$\mathbf{1 7}$ & Mixed-I type & 0.01 & 0.05 \\
\hline
\end{tabular}

Amongst them, the double-reciprocal plots of the enzyme inhibited by curcuminoid 5 are shown in Figure 2. The equilibrium constants for the binding of $\mathbf{5}$ with free enzyme, $\mathrm{K}_{\mathrm{I}}$, and with the enzyme-substrate complex, $\mathrm{K}_{\mathrm{IS}}$, were obtained from the second plots of $\mathrm{K}_{\mathrm{m}} / \mathrm{V}_{\mathrm{m}}$ (slope) and $1 / \mathrm{V}_{\mathrm{m}}$ (intercept) versus the concentrations of the inhibitors. From the data, we found that curcuminoid 5 could bind, not only with the free enzyme, but also with the enzyme-substrate complex. The $\mathrm{K}_{\mathrm{IS}}$ values were lower than $\mathrm{K}_{\mathrm{I}}$, indicating 
that curcuminoid $\mathbf{5}$ acts as a competitive-uncompetitive mixed-II type inhibitor [21,23]. These data indicated that the affinity of the inhibitor for the enzyme-substrate complex was stronger than that for the free enzyme.
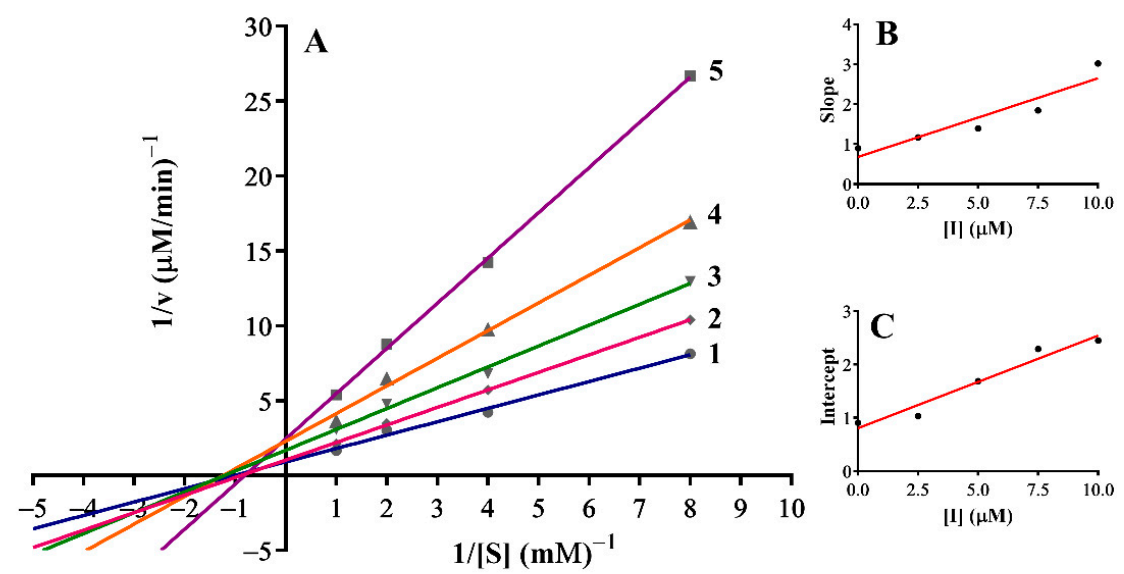

Figure 2. (A) Lineweaver-Burk plots for the inhibition of 5 on the mushroom tyrosinase for the catalysis of DOPA at $28{ }^{\circ} \mathrm{C}, \mathrm{pH}$ 6.8. Concentrations of 5 for curves $1-5$ were $0.0,2.5,5.0,7.5$ and $10.0 \mu \mathrm{M}$, respectively. The insets $(\mathbf{B}, \mathbf{C})$ represent the secondary plot of the slopes and intercepts versus concentrations of $\mathbf{5}$ to determine the inhibition constants.

In addition, the inhibitory type of curcuminoid $\mathbf{1 7}$ on mushroom tyrosinase using L-tyrosine substrate was determined by the same methods. Amongst them, the doublereciprocal plots of the enzyme inhibited by curcuminoid $\mathbf{1 7}$ are shown in Figure 3. The results showed that curcuminoid $\mathbf{1 7}$ could bind, not only with free enzyme, but also with the enzyme-substrate complex. The values of both $\mathrm{K}_{\mathrm{m}}$ and $\mathrm{V}_{\max }$ decreased with increasing inhibitor concentrations and the $\mathrm{K}_{\mathrm{I}}$ values were lower than $\mathrm{K}_{\mathrm{IS}}$, indicating that $\mathbf{1 7}$ acts as a competitive-uncompetitive mixed-I type inhibitor $[23,24]$. The competitive effect was stronger than the uncompetitive effect, meaning that curcuminoid $\mathbf{1 7}$ inhibited the free enzyme more than the enzyme-substrate complex.
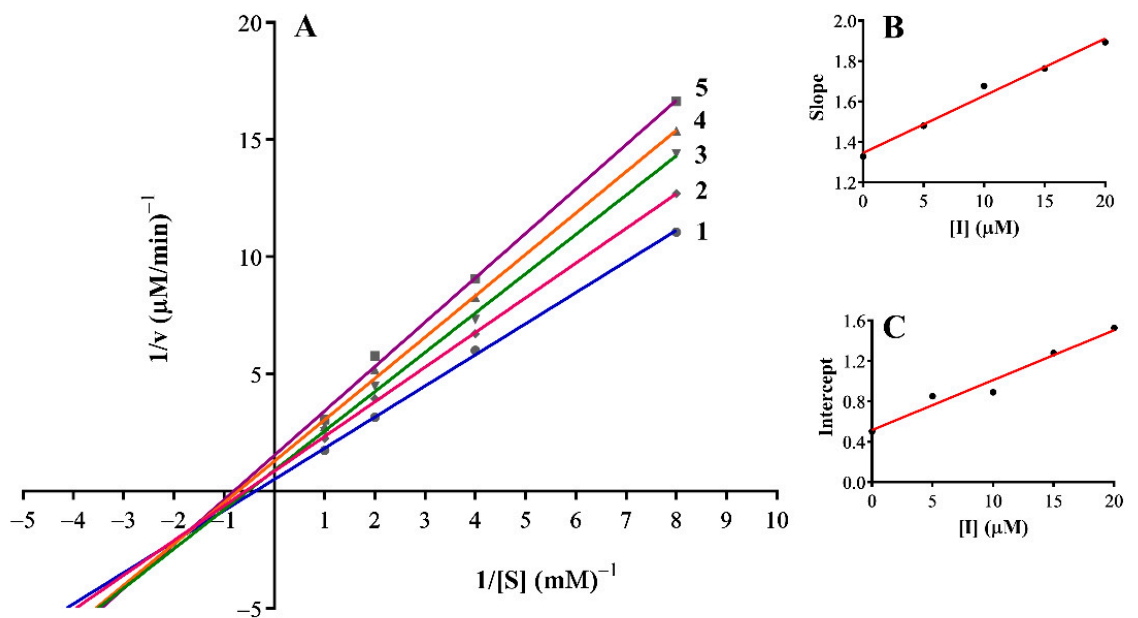

Figure 3. (A) Lineweaver-Burk plots for the inhibition of $\mathbf{1 7}$ on the mushroom tyrosinase for the catalysis of L-tyrosine at $28^{\circ} \mathrm{C}, \mathrm{pH}$ 6.8. Concentrations of $\mathbf{1 7}$ for curves $1-5$ were $0.0,5.0,10.0,15.0$ and $20.0 \mu \mathrm{M}$, respectively. The insets $(\mathbf{B}, \mathbf{C})$ represent the secondary plot of the slopes and intercepts versus concentrations of $\mathbf{1 7}$ to determine the inhibition constants.

Moreover, the inhibitory mechanisms of compound $\mathbf{1 2}$ on mushroom tyrosinase using L-tyrosine substrate were also studied from Lineweaver-Burk plots [21]. Amongst them, 
the double-reciprocal plots of the enzyme inhibited by curcuminoid $\mathbf{1 2}$ are shown in Figure 4. From these data, the enhancement of inhibitor concentration could decrease the values of $\mathrm{V}_{\max }$, but the values of $\mathrm{K}_{\mathrm{m}}$ remained the same, which indicated that curcuminoid 12 was a noncompetitive inhibitor for mushroom tyrosinase. This behavior showed that 12 could bind with both free enzyme and enzyme-substrate complex and their equilibrium constants were the same $[23,25]$. In all cases, the $K_{i}$ value was considerably lower than that recently reported for kojic acid $(9.23 \mu \mathrm{M})$ [26], which demonstrates that compounds 5, 12 and 17 are potent tyrosinase inhibitors.
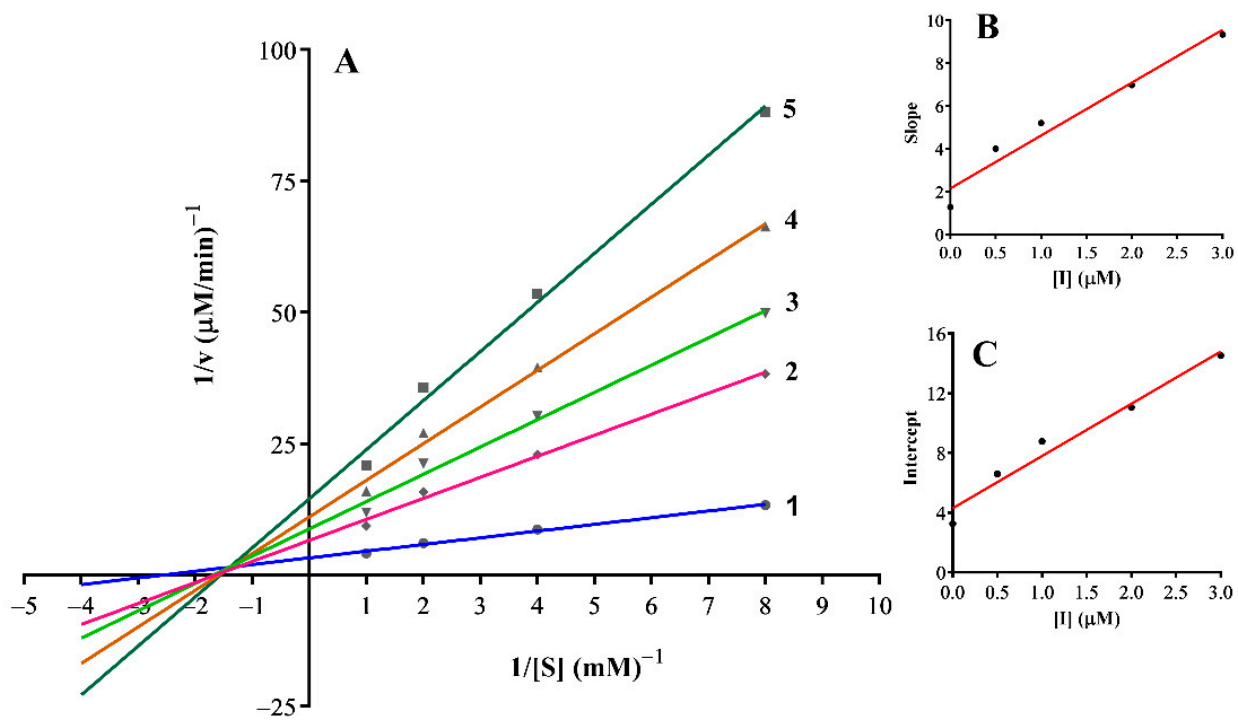

Figure 4. (A) Lineweaver-Burk plots for the inhibition of $\mathbf{1 2}$ on the mushroom tyrosinase for the catalysis of L-tyrosine at $28^{\circ} \mathrm{C}, \mathrm{pH}$ 6.8. Concentrations of $\mathbf{1 2}$ for curves $1-5$ were $0.0,0.5,1.0,2.0$ and $3.0 \mu \mathrm{M}$, respectively. The insets $(\mathbf{B}, \mathbf{C})$ represent the secondary plot of the slopes and intercepts versus concentrations of $\mathbf{1 2}$ to determine the inhibition constants.

\section{Conclusions}

In this study, we have identified a number of chemically modified curcuminoid analogues with potent inhibitory activities against tyrosinase enzyme on L-tyrosine and DOPA substrates. For the analogues with potent antityrosinase on the L-tyrosine substrate, the isoxazole analogue 12 and two reduced curcuminoid analogues, hexahydrocurcumin (16) and the $\alpha, \beta$-unsaturated curcuminoid analogue 17 , showed $\mathrm{IC}_{50}$ values of $8.3,14.6$ and 9.4 $\mu \mathrm{M}$, or 20.9-, 11.9- and 18.4-fold, respectively, more active than the reference kojic acid. For the analogues with potent antityrosinase on DOPA substrate, the dimethylated analogue 5 exhibited the strongest activity, with the $\mathrm{IC}_{50}$ value of $8.0 \mu \mathrm{M}$, followed by the pyrazoles 9 and 10, with the $\mathrm{IC}_{50}$ values of 19.7 and $19.2 \mu \mathrm{M}$. These three compounds were 16.6-, 6.7- and 6.9-fold more active than kojic acid. It is noteworthy that hexahydrocurcumin (16) may be regarded as an analogue with antityrosinase activity on both L-tyrosine substrates. The inhibitory types of curcuminoid 5 on mushroom tyrosinase were determined during the oxidation of DOPA from the Lineweaver-Burk plots and it was found that compound 5 could bind with the free enzyme and the enzyme-substrate complex. It acted as a competitive-uncompetitive mixed-II type inhibitor. These data indicated that the affinity of the inhibitor for the enzyme-substrate complex was stronger than that for the free enzyme. For the curcuminoid 17, the inhibitory type showed that it could bind, not only with the free enzyme, but also with the enzyme-substrate complex. The results indicated that $\mathbf{1 7}$ acted as a competitive-uncompetitive mixed-I type inhibitor; it inhibited the free enzyme more than the enzyme-substrate complex. These potent analogues might serve as lead compounds for further design of new potential tyrosinase inhibitors and play a potential role in the prevention and treatment of skin pigmentation disorders. 
Supplementary Materials: The following are available online at https:/ /www.mdpi.com/article/10 $.3390 /$ cosmetics8020035/s1, Figures S1-S34: The ${ }^{1} \mathrm{H}$ and ${ }^{13} \mathrm{C}$ NMR spectra of compounds 1-17.

Author Contributions: Conceptualization, A.S. and S.A.; methodology, A.A., N.N., W.P. and V.A.; software, S.A.; validation, S.A. and M.D.; formal analysis, S.A. and A.S.; investigation, A.A., N.N. and W.P.; resources, A.S. and S.A.; data curation, S.A., M.D. and A.S.; writing-original draft preparation, A.A.; writing—review and editing, A.S., W.P., V.A. and S.A..; visualization, N.N.; supervision, A.S. and S.A.; project administration, A.S. and S.A.; funding acquisition, A.S. All authors have read and agreed to the published version of the manuscript.

Funding: This research was funded by The Thailand Research Fund, grant number DBG6180030.

Institutional Review Board Statement: Not applicable.

Informed Consent Statement: Not applicable.

Data Availability Statement: Not applicable.

Acknowledgments: This work was supported by the Junior Research Fellowship Program, French Embassy, Thailand, the Center of Excellence for Innovation in Chemistry (PERCH-CIC), Ministry of Higher Education, Science, Research and Innovation, and The Research Unit in Synthetic Compounds and Synthetic Analogues from Natural Product for Drug Discovery (RSND), Burapha University. Supports from Ramkhamhaeng University and Burapha University are gratefully acknowledged.

Conflicts of Interest: The authors declare no conflict of interest.

\section{References}

1. Chang, T.-S. An updated review of tyrosinase inhibitors. Int. J. Mol. Sci. 2009, 10, 2440-2475. [CrossRef] [PubMed]

2. Sharifi-Rad, J.; Rayess, Y.E.; Rizk, A.A.; Sadaka, C.; Zgheib, R.; Zam, W.; Sestito, S.; Rapposelli, S.; Neffe-Skocińska, K.; Zielińska, D.; et al. Turmeric and its major compound curcumin on health: Bioactive effects and safety profiles for food, pharmaceutical, biotechnological and medicinal applications. Front. Pharmacol. 2020, 11, 01021. [CrossRef] [PubMed]

3. Jakubczyk, K.; Drużga, A.; Katarzyna, J.; Skonieczna-Żydecka, K. Antioxidant potential of curcumin-A meta-analysis of randomized clinical trials. Antioxidants 2020, 9, 1092. [CrossRef] [PubMed]

4. Lee, K.-H.; Aziz, F.H.; Syahida, A.; Abas, F.; Shaari, K.; Israf, D.A.; Lajis, N.H. Synthesis and biological evaluation of curcumin-like diarylpentanoid analogues for anti-inflammatory, antioxidant and anti-tyrosinase activities. Eur. J. Med. Chem. 2009, 44, 3195-3200. [CrossRef]

5. Tomeh, M.A.; Hadianamrei, R.; Zhao, X. A review of curcumin and its derivatives as anticancer agents. Int. J. Mol. Sci. 2019, 20, 1033. [CrossRef]

6. Zheng, D.; Huang, C.; Huang, H.; Zhao, Y.; Khan, M.R.U.; Zhao, H.; Huang, L. Antibacterial mechanism of curcumin: A review. Chem. Biodivers. 2020, 17, e2000171. [CrossRef]

7. Adamczak, A.; Ożarowski, M.; Karpiński, T.M. Curcumin, a natural antimicrobial agent with strain-specific activity. Pharmaceuticals 2020, 13, 153. [CrossRef] [PubMed]

8. Jennings, M.R.; Parks, R.J. Curcumin as an antiviral agent. Viruses 2020, 12, 1242. [CrossRef]

9. Nistico, S.; Tamburi, F.; Bennardo, L.; Dastoli, S.; Schipani, G.; Caro, G.; Fortuna, M.C.; Rossi, A. Treatment of telogen effluvium using a dietary supplement containing Boswellia serrata, Curcuma longa, and Vitis vinifera: Results of an observational study. Dermatol. Ther. 2019, 32, e12842. [CrossRef] [PubMed]

10. Vollono, L.; Falconi, M.; Gaziano, R.; Iacovelli, F.; Dika, E.; Terracciano, C.; Bianchi, L.; Campione, E. Potential of curcumin in skin disorders. Nutrients 2019, 11, 2169.

11. Panahi, Y.; Fazlolahzadeh, O.; Atkin, S.L.; Majeed, M.; Butler, A.E.; Johnston, T.P.; Sahebkar, A. Evidence of curcumin and curcumin analogue effects in skin diseases: A narrative review. J. Cell Physiol. 2019, 234, 1165-1178. [CrossRef] [PubMed]

12. Du, Z.-Y.; Jiang, Y.-F.; Tang, Z.-K.; Mo, R.-Q.; Xue, G.-H.; Lu, Y.-J.; Zheng, X.; Dong, C.-Z.; Zhang, K. Antioxidant and tyrosinase inhibition of polyphenolic curcumin analogs. Biosci. Biotechnol. Biochem. 2011, 75, 2351-2358. [CrossRef]

13. Bhullar, K.S.; Jha, A.; Youssef, D.; Rupasinghe, H.P.V. Curcumin and its carbocyclic analogs: Structure-activity in relation to antioxidant and selected biological properties. Molecules 2013, 18, 5389-5404. [CrossRef]

14. Jiang, Y.; Du, Z.; Xue, G.; Chen, Q.; Lu, Y.; Zheng, X.; Conney, A.H.; Zhang, K. Synthesis and biological evaluation of unsymmetrical curcumin analogues as tyrosinase inhibitors. Molecules 2013, 18, 3948-3961. [CrossRef]

15. Bukhari, S.N.; Jantan, I.; Unsal Tan, O.; Sher, M.; Naeem-ul-Hassan, M.; Qin, H.-L. Biological activity and molecular docking studies of curcumin-related $\alpha, \beta$-unsaturated carbonyl-based synthetic compounds as anticancer agents and mushroom tyrosinase inhibitors. J. Agric. Food Chem. 2014, 62, 5538-5547. [CrossRef] [PubMed]

16. Shirota, S.; Miyazaki, K.; Aiyama, R.; Ichioka, M.; Yokokura, T. Tyrosinase inhibitors from crude drugs. Biol. Pharm. Bull. 1994, 17, 266-269. [CrossRef] 
17. Nguyen, M.H.; Nguyen, H.X.; Nguyen, M.T.; Nguyen, N.T. Phenolic constituents from the heartwood of Artocapus altilis and their tyrosinase inhibitory activity. Nat. Prod. Commun. 2012, 7, 185-186. [CrossRef] [PubMed]

18. Changtam, C.; De Koning, H.P.; Ibrahim, H.; Sajid, M.S.; Gould, M.K.; Suksamrarn, A. Curcuminoid analogs with potent activity against Trypanosoma and Leishmania species. Eur. J. Med. Chem. 2010, 45, 941-956. [CrossRef]

19. Changtam, C.; Hongmanee, P.; Suksamrarn, A. Isoxazole analogs of curcuminoids with highly potent multidrug-resistant antimycobacterial activity. Eur. J. Med. Chem. 2010, 45, 4446-4457. [CrossRef]

20. Chen, J.; Sun, H.; Tao, X.; Wang, S.; Sun, A. Inhibitory mechanism and kinetics study of apple polyphenols on the activity of tyrosinase. Int. J. Food Prop. 2014, 17, 1694-1701. [CrossRef]

21. Chen, Q.-X.; Song, K.-K.; Qui, L.; Liu, X.-D.; Huang, H.; Guo, H.-Y. Inhibitory effects on mushroom tyrosinase by p-alkoxybenzoic acids. Food Chem. 2005, 91, 269-274. [CrossRef]

22. Ghani, U.; Ullah, N. New potent inhibitors of tyrosinase: Novel clues to binding of 1,3,4-thiadiazole-2(3H)-thiones, 1,3,4oxadiazole-2(3H)-thiones, 4-amino-1,2,4-triazole-5(4H)-thiones, and substituted hydrazides to the dicopper active site. Bioorg. Med. Chem. 2010, 18, 4042-4048. [CrossRef] [PubMed]

23. Zolghadri, S.; Bahrami, A.; Khan, M.T.H.; Munoz-Munoz, J.; Garcia-Molina, F.; Garcia-Canovas, F.; Saboury, A.A. A comprehensive review on tyrosinase inhibitors. J. Enzym. Inhib. Med. Chem. 2019, 34, 279-309. [CrossRef]

24. Noh, J.-M.; Lee, Y.-S. Inhibitory activities of hydroxyphenolic acid-amino acid conjugates on tyrosinase. Food Chem. 2011, 125, 953-957. [CrossRef]

25. Fan, Q.; Jiang, H.; Yuan, E.-D.; Zhang, J.-X.; Ning, Z.-X.; Qi, S.-J.; Wei, Q.-Y. Tyrosinase inhibitory effects and antioxidative activities of novel cinnamoyl amides with amino acid ester moiety. Food Chem. 2012, 134, 1081-1087. [CrossRef] [PubMed]

26. Radhakrishnan, S.; Shimmon, R.; Conn, C.; Baker, A. Design, synthesis and biological evaluation of hydroxy substituted amino chalcone compounds for antityrosinase activity in B16 cells. Bioorg. Chem. 2015, 62, 117-123. [CrossRef] 